\title{
High parity is associated with increased risk of cervical cancer: Systematic review and meta-analysis of case-control studies
}

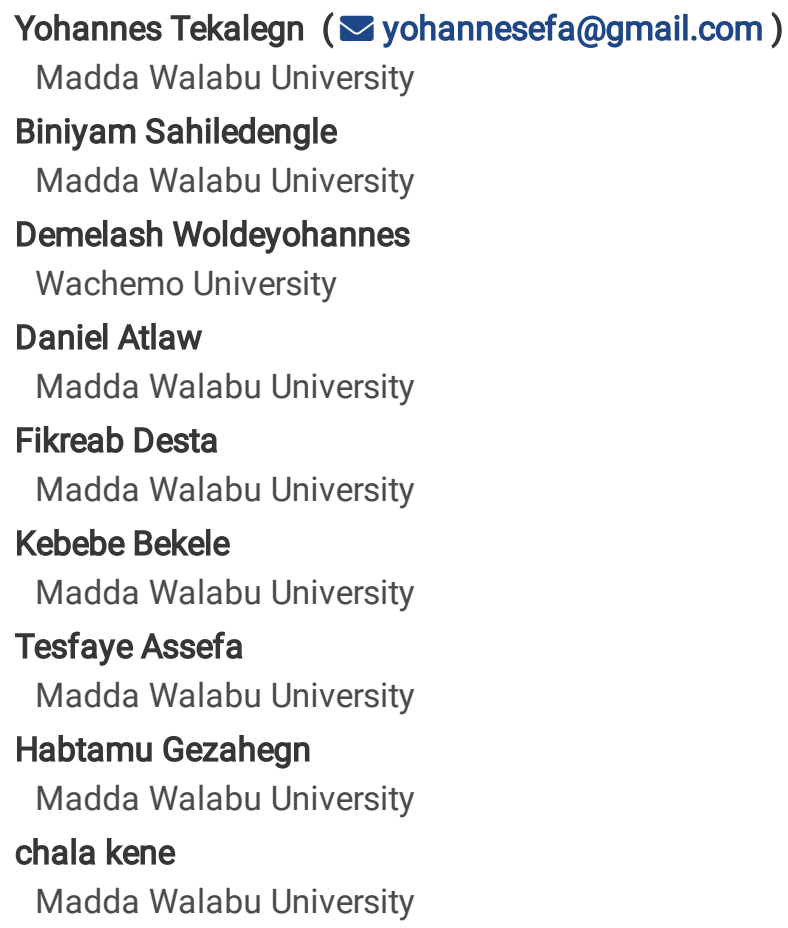

Research Article

Keywords: Parity, cervical cancer, systematic review, meta-analysis, case-control

Posted Date: April 8th, 2021

DOI: https://doi.org/10.21203/rs.3.rs-397999/v1

License: (c) (i) This work is licensed under a Creative Commons Attribution 4.0 International License. Read Full License

Version of Record: A version of this preprint was published at Women's Health on January 1st, 2022. See the published version at https://doi.org/10.1177/17455065221075904. 


\section{Abstract}

Background: Cervical cancer is the fourth most common cancer among women. High parity has long been suspected with an increased risk of cervical cancer. Evidence from the existing epidemiological studies regarding the association between parity and cervical cancer is variable and inconsistent. Therefore, the objective of this systematic review and meta-analysis was to synthesize the best available evidence on the epidemiological association between parity and cervical cancer.

Methods: MEDLINE/PubMed, HINARI, Google scholar, Science direct, and Cochrane Libraries were systematically searched. Cochrane Q statistics and 12 tests were performed to assess heterogeneity among included studies. Begg's test and egger's regression analysis were performed to assess publication bias. A random-effect meta-analysis model was used to compute pooled odds ratio of the association between parity and cervical cancer.

Results: A total of 6975 participants (1998 patients; 4977 controls) were incorporated in the 13 articles included in the final metaanalysis. The meta-analysis revealed that women with parity greater than or equal to three had 2.4 times higher odds of developing cervical cancer compared to women with parity less than three [pooled odds ratio (POR) $=2.4,95 \% \mathrm{Cl}$ : 1.9-3.2]

Conclusion: High parity is associated with an increased risk of cervical cancer. Strong epidemiological studies are recommended to further explore the mechanisms and role of parity in the causation of cervical cancer.

\section{Background}

Cancer is a group of diseases characterized by the uncontrolled growth and spread of abnormal cells (1). Cervical cancer is considered nearly completely preventable because of the generally slow progression of the disease and the availability of screening and the Human Papilloma Virus (HPV) vaccine (2). Cervical cancer is cancer that forms in tissues of the cervix, the organ connecting the uterus and the vagina. It is usually slow-growing cancer that may not have symptoms at early stages. Every year, about 528,000 new cases of cervical cancer occur among women worldwide (3).

Human Papilloma Virus (HPV) is recognized as a necessary cause of cervical cancer (4-9). However, HPV infection alone is not sufficient to cause cervical cancer and some cofactors modify the progression of the infections to cancer $(4,8)$. Evidence suggests that women's characteristics like age, number of live births or parity, number of pregnancies, age at first sexual intercourse, age at first pregnancy, history of sexually transmitted infections, having multiple sexual partners, and history of long-term oral contraceptives use play role in developing cervical cancer (10-14,14-19).

Previous studies reported a positive association between parity and cervical cancer (10,20-24). Excess risk of cervical cancer among women with high parity is believed to be linked with a high rate of cervical abnormalities during pregnancy $(25,26)$, a high detection rate of HPV among pregnant women $(27,28)$, and some studies also suggest vaginal parity makes local changes to cervical cells due to traumas during birth (11). Though several previous epidemiological studies documented parity as a risk factor for cervical cancer; the reported strength of association is variable and inconsistent. Therefore, this systematic review and metaanalysis aimed to estimate the pooled odds ratios of the association between parity and cervical cancer. This meta-analysis will highlight the strength of association between parity and cervical cancer which will, in turn, helps to ascertain risks of cervical cancer among women with high parity compared to those with low parity.

\section{Methods}

\section{Formulation of the questions}

The primary aim of this systematic review was: does high parity affect the risk of cervical cancer? If so, to what extent does high parity affect the development of cervical cancer?

\section{Search strategies}


This review was conducted according to the Preferred Reporting Items for Systematic Reviews and Meta-Analysis (PRISMA) guideline (29) (additional file 1). To get potentially relevant articles, a comprehensive search was performed in the following databases: MEDLINE/Pub Med, Hinari, Google Scholar, Science Direct, and Cochrane Library. The following key terms in combination with Boolean operators were used: (("parities"[All Fields] OR "parity"[MeSH Terms]) OR "parity"[All Fields]) AND (("uterine cervical neoplasms"[MeSH Terms] OR (("uterine"[All Fields] AND "cervical"[All Fields]) AND "neoplasms"[All Fields])) OR "uterine cervical neoplasms"[All Fields]). To ensure a comprehensive search of the literature, reference lists of included studies were scanned.

\section{Eligibility criteria}

Population: All studies reporting the association between parity and cervical cancer among women.

Exposure of interest: Parity.

Outcome of interest: cervical cancer.

Study designs: Epidemiological studies (Case-control and Cohort studies) examining the association between parity and cervical cancer were included in this review. Besides, the odds ratio (OR) examining the association between parity and cervical cancer shall be given or derived from the original studies to be considered for inclusion into the meta-analysis. Systematic reviews, crosssectional, case-report, case-series, opinion reports, letters to the editor, short communications, and qualitative studies were excluded.

Setting: This systematic review and meta-analysis included all studies reporting the association between parity and cervical cancer regardless of their study areas.

Timeframe: This review included all studies published after 2000 up to March 7, 2020. An electronic database search was conducted from February 6, 2020, to March 7, 2020.

Publication condition: This review included articles published in peer-reviewed journals.

Language: Only articles reported in English were considered.

\section{Study selection}

All identified articles through electronic databases were imported to EndNote X4 software. After removing duplicate articles, two authors (YT and BS) independently screened all articles by their title, abstract and full texts for their eligibility against the predetermined inclusion and exclusion criteria. Subsequently, identified articles were compiled together and discrepancies between the two authors were resolved through discussion to reach a consensus.

\section{Risk of bias}

We used Joanna Briggs Institutes' (JBI) Critical appraisal checklist for case-control studies (30). The tool composed of ten parameters: 1) were the groups comparable other than the presence of disease in cases or absence of disease in controls? 2) Were cases and controls matched appropriately? 3) Were the same criteria used for the identification of cases and controls? 4) Was exposure measured in a standard, valid and reliable way? 5) Was exposure measured in the same way for cases and controls? 6) Were confounding factors identified? 7) Were strategies to deal with confounding factors stated? 8) Were outcomes assessed in a standard, valid and reliable way for cases and controls? 9) Was the exposure period of interest long enough to be meaningful? 10) Was appropriate statistical analysis used? Two authors (YT and BS) evaluated the risk of bias of the full text considered to be included in the meta-analysis. The overall risk of bias was then scored according to the number of high risks of bias per study: low $(\leq 2)$, moderate (3-4), and high ( $\geq 5$ ) (additional file 2). 


\section{Data extraction}

Data were extracted on Microsoft Office Excel spreadsheet. The data extraction format is composed of the primary author's name, year of publication, study period, country, study design, study setup, number of cases, number of controls, odds ratio, and $95 \%$ confidence intervals for the association between parity and cervical cancer. Two authors (YT and BS) independently extracted the information. Any discrepancies were resolved through discussion.

\section{Statistical analysis}

Extracted data were imported into STATA version 14 software (StataCorp LP.2015, College Station, TX: USA) to perform all statistical analysis. First, odds ratios were either obtained or derived from data reported in the original studies. Then, converted to log odds ratio. Standard error (SE) for the log odds ratios (OR) were computed using SE $(\log O R)=\sqrt{ }(1 / a+1 / b+1 / c+1 / d)$. Heterogeneity between studies was assessed using Cochran's Q-statistics and $\mathrm{I}^{2}$ test. In this meta-analysis, the test statistics indicated the presence of significant heterogeneity $\left(l^{2}=78.4 \%, p<0.001\right)$. For this reason, the odds ratios were pooled using random-effect meta-analysis techniques (DerSimonian and Liard method), which accounts for the variation between studies. Natural logarithm (In) of odds ratios and their respective $95 \%$ confidence intervals were used to get pooled odds ratio of the association between parity and cervical cancer. The pooled odds ratios along with their $95 \%$ confidence intervals were presented using a forest plot. Subgroup analyses by countries of original studies were conducted. Univariate meta-regression analyses were also conducted to identify possible sources of heterogeneity. Variables considered in meta-regression were years of publication, number of cases, and number of controls. However, none of the variables were found to be a statistically significant source of heterogeneity. Publication bias of the meta-analysis was assessed using egger's test statistics, and there was no statistically significant publication bias ( $\mathrm{p}$-value $=0.4$ ).

\section{Operational definitions}

Cervical cancer: In this study, authors included studies that diagnosed cervical cancer through the histological confirmation of cancer.

Parity: Parity is defined as the number of times that a woman has given birth to a fetus with a gestational age of 24 weeks or more, regardless of whether the child was born alive or was stillborn.

High parity: In this meta-analysis, we used parity greater than or equal to three as high parity. We made this classification depending on the availability of data among included primary studies.

\section{Results}

\section{Description of articles selection}

A total of 2392 articles were identified through all databases described above. Of these, 1020 duplicate articles were removed. After screening by their title and abstract, 1340 articles were excluded. Then, 26 articles were assessed for eligibility based on predefined eligibility criteria and risk of bias assessment. Further 13 articles were excluded due to inaccessibility of full text, full articles reported in languages other than English, the outcome of interest is not reported separately, the outcome of interest is not reported, excluded after critical appraisal (additional file 3). Finally, 13 articles were included in this meta-analysis (Fig.1).

\section{Characteristics of included studies}

As described in Table 1, a total of 13 articles were included in this systematic review and meta-analysis. A total of 6975 participants (1998 patients; 4977 controls) were incorporated in the 13 articles included in the final metaanalysis. One study reported an association of parity with both Adenocarcinoma and Squamous cell carcinoma of the cervix (31); hence, both results were included in the meta-analysis. All of the included articles were casecontrol studies. Of all studies included, one study was from China, one from Côte d'Ivoire, one study from 
Ethiopia, three studies from India, two studies from Indonesia, one article from Taiwan, one article from Thailand, one article from the UK, and one study from the USA. Regarding the year of publications, the earliest article included in this meta-analysis was published in 2003 (32,33), and the latest was published in 2019 (34,35).

Table 1: List of studies included in the systematic review and meta-analysis of the association between parity and risk of cervical cancer, 2020. 


\begin{tabular}{|c|c|c|c|c|c|c|c|c|c|}
\hline No & Primary author & $\begin{array}{l}\text { Year of } \\
\text { publication }\end{array}$ & Study site & $\begin{array}{c}\text { Study } \\
\text { setups/source }\end{array}$ & $\begin{array}{l}\text { Study } \\
\text { design }\end{array}$ & $\begin{array}{l}\text { Number } \\
\text { of cases }\end{array}$ & $\begin{array}{c}\text { Number } \\
\text { of } \\
\text { controls }\end{array}$ & $\begin{array}{l}\text { Age range } \\
\text { (years) }\end{array}$ & $\begin{array}{c}\text { COR } \\
(95 \% \\
\text { CI })\end{array}$ \\
\hline 1 & Cai (36) & 2008 & China & Hospital & $\begin{array}{l}\text { Case- } \\
\text { control }\end{array}$ & 110 & 110 & $22-72$ & $\begin{array}{l}1.1 \\
(0.6- \\
1.8)\end{array}$ \\
\hline 2 & $\begin{array}{l}\text { Adjorlolo- } \\
\text { Johnson (37) }\end{array}$ & 2010 & $\begin{array}{l}\text { Côte } \\
\text { d'Ivoire }\end{array}$ & Hospital & $\begin{array}{l}\text { Case- } \\
\text { control }\end{array}$ & 132 & 120 & $18-70$ & $\begin{array}{l}4.1 \\
(2.0- \\
8.4)\end{array}$ \\
\hline 3 & Bezabih (12) & 2015 & Ethiopia & Hospital & $\begin{array}{l}\text { Case- } \\
\text { control }\end{array}$ & 60 & 120 & unreported & $\begin{array}{l}4.6 \\
(2.8- \\
7.4)\end{array}$ \\
\hline 4 & Franceschi (32) & 2003 & India & Hospital & $\begin{array}{l}\text { Case- } \\
\text { control }\end{array}$ & 193 & 210 & unreported & $\begin{array}{l}3.0 \\
(1.8- \\
4.7)\end{array}$ \\
\hline 5 & Sharma (38) & 2018 & India & Hospital & $\begin{array}{l}\text { Case- } \\
\text { control }\end{array}$ & 91 & 182 & $20-80$ & $\begin{array}{l}6.48 \\
(2.9- \\
14.2)\end{array}$ \\
\hline 6 & Thakur (39) & 2015 & India & Hospital & $\begin{array}{l}\text { Case- } \\
\text { control }\end{array}$ & 226 & 226 & unreported & $\begin{array}{l}2.8 \\
(1.9- \\
4.3)\end{array}$ \\
\hline 7 & Arfailasufandi (35) & 2019 & Indonesia & Hospital & $\begin{array}{l}\text { Case- } \\
\text { control }\end{array}$ & 100 & 100 & unreported & $\begin{array}{l}4.1 \\
(2.3- \\
7.6)\end{array}$ \\
\hline 8 & Putri (34) & 2019 & Indonesia & Hospital & $\begin{array}{l}\text { Case- } \\
\text { control }\end{array}$ & 60 & 60 & $21-30$ & $\begin{array}{l}3.5 \\
(1.7- \\
7.6)\end{array}$ \\
\hline 9 & Chen (40) & 2005 & Taiwan & Hospital & $\begin{array}{l}\text { Case- } \\
\text { control }\end{array}$ & 45 & 54 & $<36$ & $\begin{array}{l}4.9 \\
(2.0- \\
11.8)\end{array}$ \\
\hline 10 & Natphopsuk (41) & 2012 & Thailand & Hospital & $\begin{array}{l}\text { Case- } \\
\text { control }\end{array}$ & 177 & 177 & $27-81$ & $\begin{array}{l}1.7 \\
(1.11- \\
2.7)\end{array}$ \\
\hline 11 & Nesrin (42) & 2011 & Turkey & Hospital & $\begin{array}{l}\text { Case- } \\
\text { control }\end{array}$ & 209 & 1050 & unreported & $\begin{array}{l}1.6 \\
(1.17- \\
2.14)\end{array}$ \\
\hline 12 & Green (33) & 2003 & UK & $\begin{array}{l}\text { Cancer } \\
\text { registry }\end{array}$ & $\begin{array}{l}\text { Case- } \\
\text { control }\end{array}$ & 180 & 923 & $20-44$ & $\begin{array}{l}1.4 \\
(1.01- \\
2.04)\end{array}$ \\
\hline 13 & Green (33) & 2003 & UK & $\begin{array}{l}\text { Cancer } \\
\text { registry }\end{array}$ & $\begin{array}{l}\text { Case- } \\
\text { control }\end{array}$ & 180 & 923 & $20-44$ & $\begin{array}{l}1.5 \\
(1.14- \\
1.92)\end{array}$ \\
\hline 14 & Shields (43) & 2004 & USA & Hospital & $\begin{array}{l}\text { Case- } \\
\text { control }\end{array}$ & 235 & 722 & $20-74$ & $\begin{array}{l}1.7 \\
(1.14- \\
2.42)\end{array}$ \\
\hline
\end{tabular}

\section{Association between parity and cervical cancer}

As describe in Fig.2 below, thirteen case-control studies were included in this meta-analysis to determine the association between parity and cervical cancer. The studies exhibited significant heterogeneity $\left(\mathrm{I}^{2}=77.8, \mathrm{p}<\right.$ 
0.001), hence, a random effect meta-analysis model was used to estimate the pooled odds ratio. This metaanalysis revealed that parity is significantly associated with cervical cancer. The likelihood of developing cervical cancer was more than two times higher among women with high parity $(\geq 3)$ compared to their counterparts $(<3)$ $(\mathrm{OR}=2.4,95 \%$ CI: 1.9-3.2).

Figure 2: Forest plot of the individual and pooled odds ratios (OR) of association between cervical cancer and parity

\section{Subgroup analysis and exploration of heterogeneity}

As described in Fig.3, Subgroup analysis was conducted by countries where the studies were carried out. Accordingly, positive associations were observed between parity and cervical cancer in studies conducted in Côte d'Ivoire, Ethiopia, India, Taiwan, Thailand, Turkey, the UK, and the USA except the study reported from China.

Fig 3: Subgroup analysis of the association between cervical cancer and parity by countries

\section{Test of heterogeneity}

Meta-regression analysis was employed to assess potential sources of heterogeneity. Accordingly, years of publication, the number of cases and controls were not significant sources of heterogeneity (Table 2).

Table 2: Meta-regression of factors associated with the heterogeneity of the studies included in estimating the pooled effect of parity on cervical cancer

\begin{tabular}{|l|l|l|}
\hline Variables & Coefficient & P-value \\
\hline Year of publication & 0.09 & 0.413 \\
\hline Number of cases & 0.004 & 0.563 \\
\hline Number of controls & 0.0001 & 0.883 \\
\hline
\end{tabular}

\section{Discussion}

Cervical cancer is believed to be cancer emerging from infectious disease origin (44). The human papillomavirus (HPV) two types specifically, HPVs 16 and 18 explains approximately about $70 \%$ of cervical cancer cases (45). Despite the fact HPV infection is the necessary cause in the etiology of cervical cancer, HPV infection alone is not a sufficient cause for the occurrence of the cases (4). Several epidemiological studies investigated the role of different demographic, sexual, and reproductive factors in the progression of HPV infection into cervical carcinoma $(10,23,46-51)$. This systematic review and meta-analysis investigated the pooled odds ratio of the association between multiple parity and cervical cancer.

In this meta-analysis high parity is associated with a higher risk of cervical cancer. This finding is supported by the multicenter case-control study conducted by International Agency for Research on Cancer (IARC). This multicenter study reported that nulliparous women were at lower risk of cervical cancer whereas there were clear trends of increased risk of cervical cancer as the number of full-term pregnancies increased among parous women (16). Several epidemiological studies also reported a positive association between parity and cervical cancer $(46,52-55)$.

The previous studies reported an association between full-term pregnancy and cervical cancer. The possible explanations were concentrations of estrogen and progesterone level in blood are known to increase during pregnancy and reach the highest levels in the last weeks of gestation. These hormonal changes are perhaps responsible for the alterations in the junction between the squamous and columnar epithelium (transformation zone) occurring during pregnancy. Squamous metaplasia of the transformation zone also increases during pregnancy to reach a maximum during the third trimester (56). 
Some other studies have also explained the association between multiple pregnancies and cervical cancer could be due to high detection of cervical abnormalities among pregnant women $(25,26)$, probably due to migration of endocervix during pregnancy (57). There are also assumptions that traumas to the uterine cervix during vaginal delivery might be a possible explanation for the positive association between cervical cancer and parity $(21,58)$. Cesarean delivery was not associated with cervical cancer as vaginal delivery does, which might strengthen the speculation that traumas during the vaginal delivery might increase the risks (16).

A large cohort study conducted in Taiwan reported that high vaginal parity is not a sufficient cause by itself unless that women also HPV infected. They explained that if the woman is HPV infected and had high vaginal parity, the virus can easily integrate due to the birth traumas, and the risk of cervical cancer increases. However, if the woman is not HPV infected, vaginal parity doesn't make difference whether it is high or low because birth trauma can heal by itself (59). Similarly, a multicenter case-control study by IARC reported that women with baseline HPV infection and multiple pregnancies had a higher risk of developing cervical cancer compared to women with a low number of pregnancies (16).

Even though several epidemiological studies examined the association between cervical cancer and different reproductive characteristics of women; the role of high parity and mechanisms in the causation of cervical cancer is unclear. There are several hypotheses regarding the effect of parity in the development of cervical cancer. Few studies suggest that vaginal parity could cause trauma to the cervix which could be responsible for cervical cancer developments and some other studies justified the role of parity by explaining hormonal changes during pregnancy might be responsible for the changes in cervical cells. There are also studies speculating high parity might be associated with a longer duration of oral contraceptive use which might, in turn, leads to cervical cancer development. Despite there are debates regarding the mechanism and role of parity in the development of cervical cancer, there is plenty of strong evidence which supports the positive association between parity and cervical cancer.

\section{Limitations}

This meta-analysis didn't examine the effect of vaginal or cesarean parity separately. Also, this study didn't explore separately the interaction between HPV infection and high parity on cervical cancer development. This meta-analysis included case-control studies which were published in the English language only.

\section{Conclusion}

This meta-analysis revealed that parity is positively associated with cervical cancer risks. Women with high parity had higher odds of developing cervical cancer compared to those with relatively low parity. Epidemiological studies with strong designs are recommended to examine the mechanisms and role of parity in the causation of cervical cancers.

\section{Abbreviations}

Cl: Confidence interval; HPV: Human Papilloma Virus; OR: Odds ratio

\section{Declarations}

Authors' contributions

YT: Conceptualized, designed the study and data curation, performed the analysis, wrote, and approved the final manuscript. BS \&DW: Data curation and performed the analysis, and approved the final manuscript DA, FD, KB, TA, HG \& CK: Contribute to the analysis, critically reviewed the manuscript, and approved the final manuscript. All authors read and approved the final manuscript before submission.

Funding

Not applicable

Availability of data and materials

Page $8 / 14$ 
All relevant data are within the manuscript and its supporting information files.

Ethics approval and consent to participate

Not applicable

Consent for publication

Not applicable

Competing interests

The author declares that they have no competing interests

Acknowledgment

Not applicable

\section{References}

1. American Cancer Society. Cancer Facts \& Figures 2018. Atlanta: American Cancer Society; 2018.

2. American College of Obstetricians and Gynecologists, Committee on Adolescent Health Care, Immunization Expert Work Group. Committee Opinion Number 641, human papillomavirus vaccination.2015;126:e38-43.

3. ACF (Anti cancer Fund). Cervical Cancer: a guide for patients - Information based on ESMO Clinical Practice Guidelines. 2012. v.2012.1.

4. Bosch FX, De Sanjosé S. Chapter 1: Human papillomavirus and cervical cancer-burden and assessment of causality. JNCI Monogr. 2003;2003(31):3-13.

5. Waggoner SE. Cervical cancer. The Lancet. 2003;361(9376):2217-25.

6. Munoz N. Human papillomavirus and cancer: the epidemiological evidence. J Clin Virol. 2000;19(1-2):1-5.

7. Bosch FX, Lorincz A, Muñoz N, Meijer C, Shah KV. The causal relation between human papillomavirus and cervical cancer. J Clin Pathol. 2002;55(4):244-65.

8. Bosch FX, de Sanjosé S. The epidemiology of human papillomavirus infection and cervical cancer. Dis Markers. 2007;23(4):213-27.

9. Steben M, Duarte-Franco E. Human papillomavirus infection: epidemiology and pathophysiology. Gynecol Oncol. 2007;107(2):S2-5.

10. Castellsagué X, Munoz N. Chapter 3: Cofactors in human papillomavirus carcinogenesis-role of parity, oral contraceptives, and tobacco smoking. JNCI Monogr. 2003;2003(31):20-8.

11. Castellsague X, Bosch FX, Munoz N. Environmental co-factors in HPV carcinogenesis. Virus Res. 2002;89(2):191-9.

12. Bezabih M, Tessema F, Sengi H, Deribew A. Risk Factors Associated with Invasive Cervical Carcinoma among Women Attending Jimma University Specialized Hospital, Southwest Ethiopia: A Case Control Study. Ethiop J Health Sci. 2016/03/08 ed. 2015 Oct;25(4):345-52.

13. Teame H, Gebremariam L, Kahsay T, Berhe K, Gebreheat G, Gebremariam G. Factors affecting utilization of cervical cancer screening services among women attending public hospitals in Tigray region, Ethiopia, 2018; Case control study. PLoS One. 2019/03/15 ed. 2019;14(3):e0213546.

14. Getinet M, Gelaw B, Sisay A, Mahmoud EA, Assefa A. Prevalence and predictors of Pap smear cervical epithelial cell abnormality among HIV-positive and negative women attending gynecological examination in cervical cancer screening center at Debre Markos referral hospital, East Gojjam, Northwest Ethiopia. BMC Clin Pathol. 2015;15(1):16.

15. Moreno V, Bosch FX, Muñoz N, Meijer CJLM, Shah KV, Walboomers JMM, et al. Effect of oral contraceptives on risk of cervical cancer in women with human papillomavirus infection: the IARC multicentric case-control study. The Lancet.

2002;359(9312):1085-92. 
16. Munoz N, Franceschi S, Bosetti C, Moreno V, Herrero R, Smith JS, et al. Role of parity and human papillomavirus in cervical cancer: the IARC multicentric case-control study. Lancet. 2002/04/12 ed. 2002 Mar 30;359(9312):1093-101.

17. Muwonge R, Ngo Mbus L, Ngoma T, Gombe Mbalawa C, Dolo A, da Ganda Manuel M, et al. Socio-demographic and reproductive determinants of cervical neoplasia in seven sub-Sahara African countries. Cancer Causes Control. 2016;27(12):1437-46.

18. Vaccarella S, Herrero R, Dai M, Snijders PJF, Meijer CJLM, Thomas JO, et al. Reproductive factors, oral contraceptive use, and human papillomavirus infection: pooled analysis of the IARC HPV prevalence surveys. Cancer Epidemiol Prev Biomark. 2006;15(11):2148-53.

19. Reproductive factors, oral contraceptive use, and human papillomavirus infection: pooled analysis of the IARC HPV prevalence surveys. Cancer Epidemiol Biomark Prev Publ Am Assoc Cancer Res Cosponsored Am Soc Prev Oncol. 2006;15(11):2148-53.

20. Hinkula M, Pukkala E, Kyyrönen P, Laukkanen P, Koskela P, Paavonen J, et al. A population-based study on the risk of cervical cancer and cervical intraepithelial neoplasia among grand multiparous women in Finland. Br J Cancer. 2004;90(5):1025-9.

21. BRINTON LA, REEVES WC, BRENES MM, HERRERO R, DE BRIITON RC, GAITAN E, et al. Parity as a risk factor for cervical cancer. Am J Epidemiol. 1989;130(3):486-96.

22. Cancer IC of ES of C. Cervical carcinoma and reproductive factors: collaborative reanalysis of individual data on 16,563 women with cervical carcinoma and 33,542 women without cervical carcinoma from 25 epidemiological studies. Int J Cancer. 2006;119(5):1108-24.

23. Mufioz N, Franceschi S, Bosetti C, Moreno V, Herrero R, Shah KV, et al. Role of parity and human papillomavirus in cervical cancer: the IARC multicentric casecontrol study. Lancet. 2002;359(9312):1093-101.

24. Abacjew-Chmyłk AO, Chmyłko $t$, Wydra DG, Olszewska H, Kobiela P, Ciach K. Multiple multiparity is a negative prognostic factor for endometrial cancer in Poland. Ginekol Pol. 2016;87(3):178-82.

25. Mac Gregor JE,Teper S. Uterine cervical cytology and young women. Lancet 1978; I:1029-31.

26. Orr JW, Shingleton HM. Cancer in pregnancy. Chicago: Year Book Medical Publishers, Inc., 1983.

27. Garry R, Jones R. Relationship between cervical condylomata, pregnancy and subclinical papilloma virus infection.J Reprod Med 1985;5:393-9.

28. Schneider A,Hotz M, Gissmann L. Increased prevalence of human papilloma viruses i $\mathrm{n}$ the lower genital tract of pregnant women. Int J Cancer 1987; 40:198-201.

29. Shamseer L, Moher D, Clarke M, Ghersi D, Liberati A, Petticrew M, et al. Preferred reporting items for systematic review and meta-analysis protocols (PRISMA-P) 2015: elaboration and explanation. Bmj. 2015;349:g7647.

30. Moola S, Munn Z, Tufanaru C, Aromataris E, Sears K, Sfetcu R, et al. Chapter 7: Systematic reviews of etiology and risk. Joanna Briggs Inst Rev Man Joanna Briggs Inst. 2017;2019-05.

31. Green J, Berrington de Gonzalez A, Smith JS, Franceschi S, Appleby P, Plummer M, et al. Human papillomavirus infection and use of oral contraceptives. Br J Cancer. 2003/05/29 ed. 2003 Jun 2;88(11):1713-20.

32. Franceschi S, Rajkumar T, Vaccarella S, Gajalakshmi V, Sharmila A, Snijders PJF, et al. Human papillomavirus and risk factors for cervical cancer in Chennai, India: A case-control study. Int J Cancer. 2003;107(1):127-33.

33. Green J, Berrington de Gonzalez A, Sweetland S, Beral V, Chilvers C, Crossley B, et al. Risk factors for adenocarcinoma and squamous cell carcinoma of the cervix in women aged 20-44 years: the UK National Case-Control Study of Cervical Cancer. Br J Cancer. 2003/12/04 ed. 2003 Dec 1;89(11):2078-86.

34. Putri AR, Khaerunnisa S, Yuliati I. Cervical Cancer Risk Factors Association in Patients at the Gynecologic-Oncology Clinic of Dr. Soetomo Hospital Surabaya. Indones J Cancer. 2019;13(4):104.

35. Arfailasufandi R, Mudigdo A, Sudiyanto A. The effect of obesity, oral contraceptive and passive smoking on the risk of cervical cancer. J Epidemiol Public Health. 2019;4(3):189-97.

36. Cai HB, Ding XH, Zhou YF, Lie DM. Risk factors for cervical cancer in China: a case-control study. Eur J Gynaecol Oncol. 2008/04/05 ed. 2008;29(1):72-5.

37. Adjorlolo-Johnson G, Unger ER, Boni-Ouattara E, Touré-Coulibaly K, Maurice C, Vernon SD, et al. Assessing the relationship between HIV infection and cervical cancer in Cote d'Ivoire: a case-control study. BMC Infect Dis. 2010;10(1):242. 
38. Sharma P, Pattanshetty SM. A study on risk factors of cervical cancer among patients attending a tertiary care hospital: A case-control study. Clin Epidemiol Glob Health. 2018;6(2):83-7.

39. Thakur A, Gupta B, Gupta A, Chauhan R. Risk factors for cancer cervix among rural women of a hilly state: a case-control study. Indian J Public Health. 2015/03/12 ed. 2015 Jan;59(1):45-8.

40. Chen T-C, Lee J-Y, Wang S-Y, Chang C-L, Yang Y-C. Relevant factors for cervical cancer among young women in Taiwan. Taiwan J Obstet Gynecol. 2005;44(2):143-7.

41. Natphopsuk S, Settheetham-Ishida W, Sinawat S, Pientong C, Yuenyao P, Ishida T. Risk factors for cervical cancer in northeastern Thailand: detailed analyses of sexual and smoking behavior. Asian Pac J Cancer Prev. 2012;13(11):5489-95.

42. Nesrin R, Kilic D. Risk factors for cervical cancer: results from a hospital-based case-control study. Int J Hematol Oncol. 2011;28(4):153-9.

43. Shields TS, Brinton LA, Burk RD, Wang SS, Weinstein SJ, Ziegler RG, et al. A case-control study of risk factors for invasive cervical cancer among US women exposed to oncogenic types of human papillomavirus. Cancer Epidemiol Prev Biomark. 2004;13(10):1574-82.

44. Viscidi RP, Shah KV. Chapter 156 - Papillomaviruses. In: Cohen J, Opal SM, Powderly WG, editors. Infectious Diseases (Third Edition) [Internet]. London: Mosby; 2010. p. 1565-9. Available from: https://www.sciencedirect.com/science/article/pii/B9780323045797001568

45. Castellsagué X. Natural history and epidemiology of HPV infection and cervical cancer. Gynecol Oncol. 2008;110(3):S4-7.

46. Luhn P, Walker J, Schiffman M, Zuna RE, Dunn ST, Gold MA, et al. The role of co-factors in the progression from human papillomavirus infection to cervical cancer. Gynecol Oncol. 2013;128(2):265-70.

47. Cox JT. The development of cervical cancer and its precursors: what is the role of human papillomavirus infection? Curr Opin Obstet Gynecol. 2006;18:s5-13.

48. Franco EL, Duarte-Franco E, Ferenczy A. Cervical cancer: epidemiology, prevention and the role of human papillomavirus infection. Cmaj. 2001;164(7):1017-25.

49. Kyrgiou M, Mitra A, Moscicki A-B. Does the vaginal microbiota play a role in the development of cervical cancer? Transl Res. 2017;179:168-82.

50. Melin A, Sparén P, Bergqvist A. The risk of cancer and the role of parity among women with endometriosis. Hum Reprod. 2007;22(11):3021-6.

51. Misra JS, Das V, Srivastava AN, Singh U. Role of different etiological factors in progression of cervical intraepithelial neoplasia. Diagn Cytopathol. 2006/09/07 ed. 2006 Oct;34(10):682-5.

52. Thulaseedharan JV, Malila N, Hakama M, Esmy PO, Cheriyan M, Swaminathan R, et al. Socio demographic and reproductive risk factors for cervical cancer - a large prospective cohort study from rural India. Asian Pac J Cancer Prev. 2012/09/04 ed. 2012;13(6):2991-5.

53. Matos A, Moutinho J, Pinto D, Medeiros R. The influence of smoking and other cofactors on the time to onset to cervical cancer in a southern European population. Eur J Cancer Prev. 2005/09/22 ed. 2005 Oct;14(5):485-91.

54. Paramita S. High parity and hormonal contraception use as risk factors for cervical cancer in East Kalimantan. 2010;

55. Wilson HG, Marchbanks PA. \# 3 Parity, age at first birth, and risk of invasive cervical cancer: Meta-analyses. Ann Epidemiol. 2002;12(7):490-1.

56. Singer A. The uterine cervix from adolescence to the menopause. Br J Obstet Gynaecol. 1975/02/01 ed. 1975 Feb;82(2):8199.

57. Ostergard DR. The effect of pregnancy on the cervical squamocolumnar junction in patients with abnormal cervical cytology. Am J Obstet Gynecol. 1979;134(7):759-60.

58. Hildesheim A, Herrero R, Castle PE, Wacholder S, Bratti M, Sherman M, et al. HPV co-factors related to the development of cervical cancer: results from a population-based study in Costa Rica. Br J Cancer. 2001;84(9):1219-26.

59. Liao SF, Lee WC, Chen HC, Chuang LC, Pan MH, Chen CJ. Baseline human papillomavirus infection, high vaginal parity, and their interaction on cervical cancer risks after a follow-up of more than 10 years. Cancer Causes Control. 2012/03/28 ed. 2012 May;23(5):703-8. 


\section{Figures}

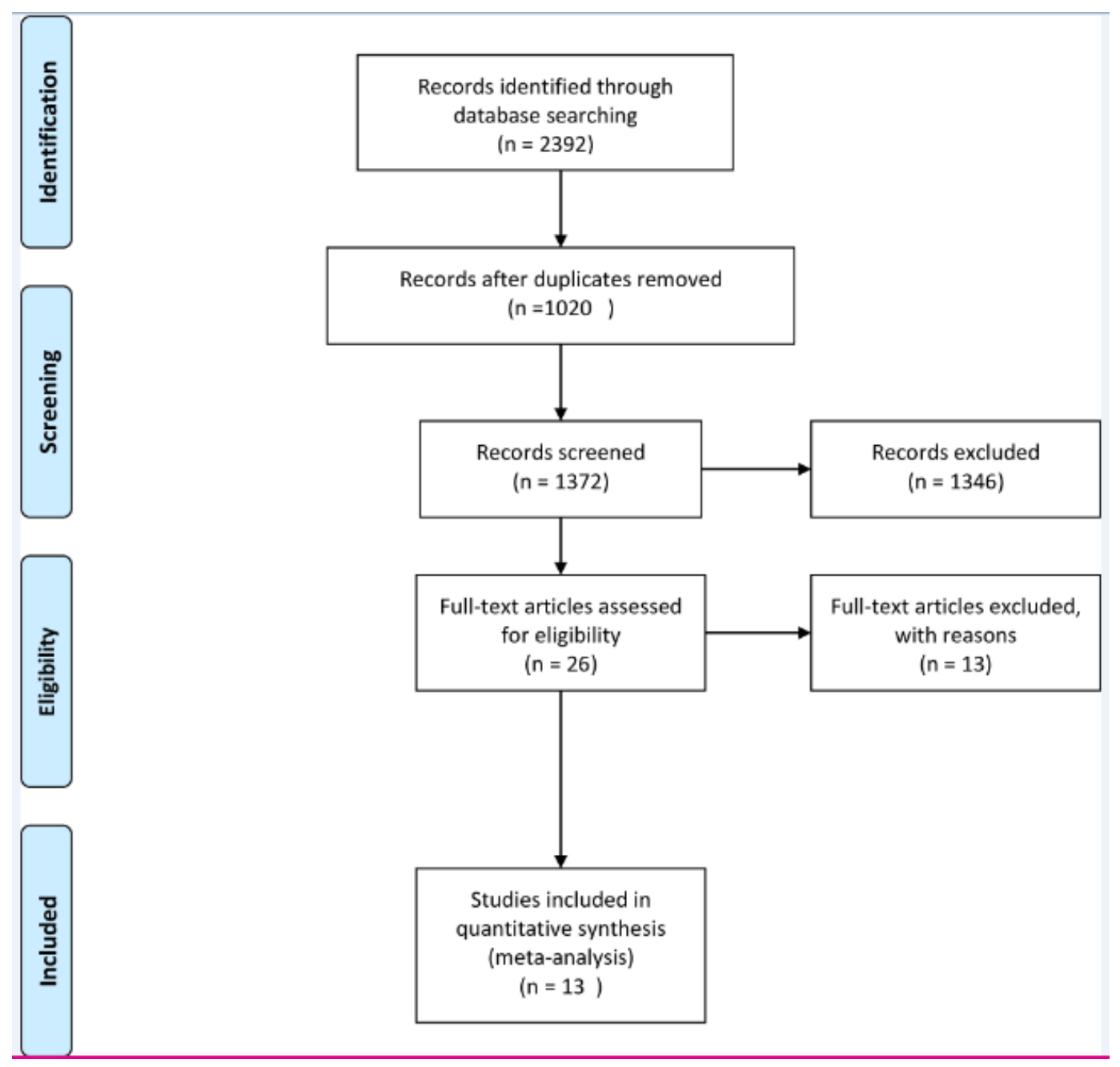

Figure 1

Study flowchart. 
Study $\%$

ID

OR $(95 \% \mathrm{Cl}) \quad$ Weight

Adjorlolo-Johnson (2010)

Arfailasufandi (2019)

Cai (2008)

Chen (2005)

Franceschi (2003)

Green (2003)

Green (2003)

Natphopsuk (2012)

Putri (2019)

Sharma (2018)

Shields (2004)

Thakur (2015)

Bezabih (2015)

Nesrin (2011)

Overall $(\mathrm{I}$-squared $=77.8 \%, p=0.000$ )

NOTE: Weights are from random effects analysis

$$
.0705
$$

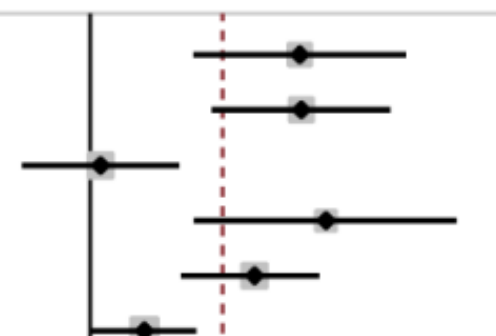

$4.10(2.00,8.40) \quad 5.71$

$4.14(2.27,7.57) \quad 6.53$

$1.07(0.63,1.82) \quad 7.08$

$4.90(2.01,11.83) 4.67$

$3.02(1.84,4.68) \quad 7.57$

$1.44(1.01,2.04) \quad 8.45$

$1.48(1.14,1.92) \quad 9.06$

$1.73(1.11,2.70) \quad 7.75$

$3.54(1.66,7.58) \quad 5.43$

$6.48(2.94,14.19) 5.26$

$1.66(1.14,2.42) \quad 8.26$

$2.84(1.89,4.29) \quad 8.01$

$4.60(2.81,7.43) \quad 7.42$

$1.59(1.17,2.14) \quad 8.79$

$2.44(1.87,3.17) \quad 100.00$

1

14.2

Figure 2

Forest plot of the individual and pooled odds ratios (OR) of association between cervical cancer and parity 


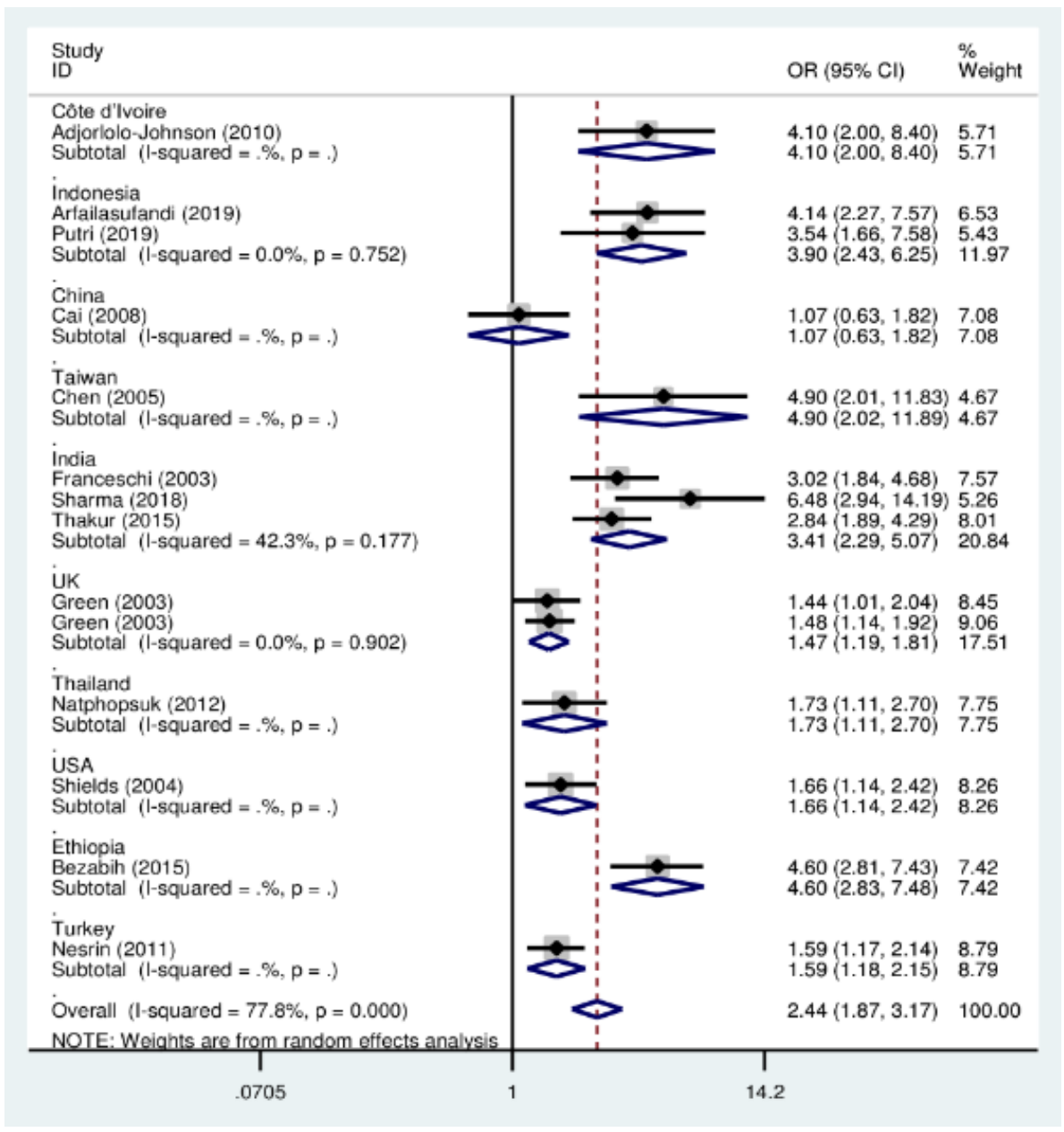

\section{Figure 3}

Subgroup analysis of the association between cervical cancer and parity by countries

\section{Supplementary Files}

This is a list of supplementary files associated with this preprint. Click to download.

- additionalfile1.docx

- additionalfile2.xlsx

- additionalfile3.docx 